\title{
Retinoids induce differentiation and downregulate telomerase activity and N-Myc to increase sensitivity to flavonoids for apoptosis in human malignant neuroblastoma SH-SY5Y cells
}

\author{
ARABINDA DAS ${ }^{1}$, NAREN L. BANIK ${ }^{1}$ and SWAPAN K. RAY ${ }^{2}$ \\ ${ }^{1}$ Division of Neurology, Department of Neurosciences, Medical University of South Carolina, \\ Charleston, SC 29425; ${ }^{2}$ Department of Pathology, Microbiology and Immunology, \\ University of South Carolina School of Medicine, Columbia, SC 29209, USA
}

Received May 13, 2008; Accepted August 4, 2008

DOI: 10.3892/ijo_00000201

\begin{abstract}
Human malignant neuroblastoma is characterized by poor differentiation and uncontrolled proliferation of immature neuroblasts. Retinoids such as all-trans-retinoic acid (ATRA), 13-cis-retinoic acid (13-CRA), and N-(4hydroxyphenyl) retinamide (4-HPR) at low doses are capable of inducing differentiation, while flavonoids such as (-)epigallocatechin-3-gallate (EGCG) and genistein (GST) at relatively high dose can induce apoptosis. We used combination of retinoid and flavonoid for controlling growth of malignant neuroblastoma SH-SY5Y cells. Cells were treated with a retinoid ( $1 \mu \mathrm{M}$ ATRA, $1 \mu \mathrm{M} 13$-CRA, or $0.5 \mu \mathrm{M}$ 4-HPR) for 7 days and then with a flavonoid (25 $\mu \mathrm{M}$ EGCG or $25 \mu \mathrm{M}$ GST) for $24 \mathrm{~h}$. Treatment of cells with a low dose of a retinoid for 7 days induced neuronal differentiation with downregulation of telomerase activity and N-Myc but overexpression of neurofilament protein (NFP) and subsequent treatment with a relatively high dose of a flavonoid for $24 \mathrm{~h}$ increased apoptosis in the differentiated cells. Besides, retinoids reduced the levels of inflammatory and angiogenic factors. Apoptosis was associated with increases in intracellular free $\left[\mathrm{Ca}^{2+}\right]$, Bax expression, cytochrome $c$ release from mitochondria and activities of calpain and caspases. Decreases in expression of calpastatin (endogenous calpain inhibitor) and baculovirus inhibitor-of-apoptosis repeat containing (BIRC) proteins (endogenous caspase inhibitors) favored apoptosis. Treatment of SH-SY5Y cells with EGCG activated caspase-8, indicating induction of the receptormediated pathway of apoptosis. Based on our observation, we conclude that combination of a retinoid and a flavonoid
\end{abstract}

Correspondence to: Professor Swapan K. Ray, Department of Pathology, Microbiology and Immunology, University of South Carolina School of Medicine, 6439 Garners Ferry Road, Building 2, Room C11, Columbia, SC 29209, USA

E-mail: swapan.ray@uscmed.sc.edu

Key words: apoptosis, caspases, flavonoids, neuroblastoma, retinoids worked synergistically for controlling the malignant growth of human neuroblastoma cells.

\section{Introduction}

The clinical hallmark of neuroblastoma includes heterogeneity and the likelihood of tumor progression varies widely according to age at diagnosis and extent of the disease (1). A number of prognostic parameters for this disease have been identified, including age, loss of heterozygosity at chromosome 1p36, DNA ploidy, histopathological stage and amplification of the N-Myc proto-oncogene. The latter condition is strongly correlated with advanced disease, insensitivity to chemotherapy, and poor outcome (2). The long-term survival rate of such high-risk patients has remained very low over the last decades. This situation has called for development of innovative therapeutic approaches. In recent years, the concept of 'combination therapy' has gained considerable interest. We applied this strategy to a human malignant neuroblastoma cell line representing immature multipotent cells lacking differentiation to induce terminal differentiation and permanent cell-cycle arrest by a retinoid that sensitized the cells to a flavonoid for increasing apoptosis.

Retinoid can induce differentiation of neuroblastoma cell lines in vitro and are being employed in the therapy of neuroblastoma patients who have thereby shown increase in survival rates (3). All-trans retinoic acid (ATRA) and 13-cis retinoic acid (13-CRA) induce differentiation in neuroblastoma cells and have been used in clinical trials in children with advanced neuroblastoma (4). While natural retinoid as a differentiationpromoting agent has entered clinical trials, it is only recently that the synthetic retinoid $\mathrm{N}$-(4-hydroxyphenyl)retinamide (4-HPR) has been found to be of potential clinical value in cancer chemoprevention and treatment. Thus far, no extensive amounts of differentiation data exist on the effects of 4-HPR on neural crest-derived tumor cells (5). Besides, very little is known about the effects of retinoids on the expression of angiogenic factors such as vascular endothelial growth factor (VEGF) that may fuel the malignant growth of neuroblastoma cells. If retinoids at a low dose can induce differentiation in neuroblastoma cells and act synergistically with apoptosisinducing agents, this combination strategy can provide 
opportunities for controlling the malignant growth of neuroblastoma.

Flavonoids are polyphenolic compounds that are ubiquitous in plants. The role of dietary flavonoids in cancer prevention is widely recognized (6). Epigallocatechin-3-gallate (EGCG), a major polyphenol found in green tea, is a widely studied chemopreventive agent with potential anti-cancer activity (6). The anti-tumor mechanism of EGCG in culture is due to modulation of the expression of key molecules in cell-cycle progression, inhibition of the inflammatory molecule nuclear factor- $\mathrm{\kappa}$ B $(\mathrm{NF}-\kappa \mathrm{B})$, binding to Fas, and activation of mitogenactivated protein kinase cascade (7). Genistein (GST) is a natural isoflavonoid found in Leguminosae. This isoflavonoid has been shown to have a strong inhibitory effect on protein tyrosine kinase and it can cause cell-cycle arrest and apoptosis in leukemic cells (8). GST substantially inhibited the growth of five tumor cell lines (N2A, JC, SKNSH, MSN and Lan5) through induction of apoptosis and modulation of protein tyrosine kinase activity and N-Myc expression (9).

This investigation was designed to examine a dual approach for controlling the malignant growth of neuroblastoma by promoting differentiation with a retinoid (ATRA, 13-CRA, or 4-HPR) and increasing apoptosis with a flavonoid (EGCG or GST).

\section{Materials and methods}

Cell culture and treatments. Human malignant (N-type) neuroblastoma SH-SY5Y cell line was purchased from the American Type Culture Collection (ATCC, Manassas, VA, USA). Cells were grown in $75-\mathrm{cm}^{2}$ flasks containing $10 \mathrm{ml}$ of RPMI-1640 (Gibco, Grand Island, NY, USA) supplemented with $10 \%$ fetal bovine serum (FBS) and $1 \%$ penicillin and streptomycin in a fully-humidified incubator containing $5 \%$ $\mathrm{CO}_{2}$ at $37^{\circ} \mathrm{C}$. Prior to drug treatments, the cells were starved in RPMI-1640 supplemented with 1\% FBS for $24 \mathrm{~h}$. ATRA, 13-CRA, and 4-HPR (Sigma Chemical, St. Louis, MO, USA) were dissolved in dimethyl sulfoxide (DMSO) and stored as aliquots of $1000 \mathrm{x}$ stocks at $-70^{\circ} \mathrm{C}$. Because of light sensitivity of ATRA, 13-CRA, and 4-HPR, all incubations involving retinoids were performed under subdued lighting. The concentration of DMSO in each experiment was always $\leq 0.01 \%$, which was not toxic and did not induce differentiation. Dose-response studies were conducted to determine the suitable doses of the drugs used for induction of apoptosis in the experiments. Finally, cells were treated with $25 \mu \mathrm{M}$ EGCG and $25 \mu \mathrm{M}$ GST for $24 \mathrm{~h}$ for induction of apoptotic death. Following treatments, apoptosis was determined morphologically and biochemically. The cells were also examined for alterations in expression and activity of proteins related to apoptosis.

Methylene blue staining for detection of morphological features of differentiation. SH-SY5Y cells were grown in monolayer in 9-cm diameter plates in absence and presence of $1 \mu \mathrm{M}$ ATRA, $1 \mu \mathrm{M}$ 13-CRA, or $0.5 \mu \mathrm{M}$ 4-HPR for 7 days. Culture medium was aspirated and washed twice with ice-cold PBS, pH 7.4. Each plate was placed on ice and $5 \mathrm{ml}$ of ice-cold $50 \%(\mathrm{v} / \mathrm{v})$ ethanol was added to fix the cells. Ethanol was aspirated followed by the addition of $5 \mathrm{ml}$ of ice-cold $0.2 \%$ (w/v) methylene blue solution (made up in 50\% ethanol). Cells were stained for $30 \mathrm{sec}$, washed twice with ice-cold water and the plates were dried in the air. Cells were examined under the light microscope at 400x magnification.

Wright staining and ApopTag peroxidase assay for morphological and biochemical features of apoptosis. SHSY5Y cells from each treatment were sedimented onto the microscopic slide and fixed in methanol before examination of apoptosis by Wright staining and ApopTag assay $(10,11)$. Wright staining detected characteristic apoptotic features such as chromatin condensation, cell-volume shrinkage, and membrane-bound apoptotic bodies. ApopTag assay kit (Intergen, Purchase, NY, USA) was used for biochemical detection of DNA fragmentation in apoptotic cells. The nuclei containing DNA fragments were stained dark brown with ApopTag assay and were not counterstained with methyl green that, however, stained normal nuclei pale to medium green. After ApopTag assay, cells were counted to determine percentage of apoptosis.

Telomerase activity assay. Telomerase activity was examined using the telomerase repeat amplification protocol (TRAP) (10). Briefly, cells were washed once with ice-cold PBS and later with ice-cold wash buffer (10 mM HEPES-KOH, $\mathrm{pH} 7.5,1.5 \mathrm{mM} \mathrm{MgCl} 2,10 \mathrm{mM} \mathrm{KCl}, 1 \mathrm{mM}$ DTT). Cells were lysed in ice-cold lysis buffer (10 mM Tris- $\mathrm{HCl}, \mathrm{pH} 7.5,1 \mathrm{mM}$ $\mathrm{MgCl}_{2}, 1 \mathrm{mM}$ EGTA, $0.1 \mathrm{mM}$ PMSF, $0.5 \%$ CHAPS, $10 \%$ glycerol) for $30 \mathrm{~min}$ on ice and centrifuged in a microfuge at $4^{\circ} \mathrm{C}$. The cells are homogenized and stored on ice for $30 \mathrm{~min}$. The supernatant was removed and quick-frozen on dry ice. The protein concentration was measured by Coomassie Brilliant Blue assay. The TRAP reaction products were electrophoresed on $12 \%$ polyacrylamide gels. After ethidium bromide staining, the gels were examined under UV (303 nm) light and photographed.

Determination of intracellular free $\left[\mathrm{Ca}^{2+}\right]$ using Fura-2 assay. The level of intracellular free $\left[\mathrm{Ca}^{2+}\right]$ was measured in human neuroblastoma SH-SY5Y cells using the fluorescence $\mathrm{Ca}^{2+}$ indicator Fura-2/AM, as described previously (6). The value of $\mathrm{K}_{\mathrm{d}}$, a cell-specific constant, was determined experimentally to be $0.451 \mu \mathrm{M}$ for the SH-SY5Y cells using standards of the Calcium Calibration Buffer kit with magnesium (Molecular Probes, Eugene, OR, USA).

Analysis of mRNA expression. Extraction of total RNA, reverse transcription-polymerase chain reaction (RT-PCR) and agarose gel electrophoresis were performed, as we described previously (11). All human primers for RT-PCR experiments were designed using human cDNA sequences of specific genes (Table I) and Oligo software (National Biosciences, Plymouth, MN, USA). The level of ß-actin gene expression served as an internal control.

Antibodies. Monoclonal antibody against $\alpha$-spectrin (Affiniti, Exeter, UK) was used to measure the activities of calpain and caspase-3. Monoclonal antibody against $\beta$-actin (clone AC-15, Sigma Chemical) was used to standardize protein loadings on the gels. The secondary antibody used was goat anti-mouse 
Table I. Human primers used to determine levels of mRNA expression of specific genes.

\begin{tabular}{|c|c|c|}
\hline Gene & Primer sequence & Product size (bp) \\
\hline B-Actin & $\begin{array}{l}\text { Sense: 5'-TAT CCC TGT ACG CCT CT-3' } \\
\text { Antisense: 5'-AGG TCT TTG CGG ATG T-3' }\end{array}$ & 460 \\
\hline $\operatorname{Bax} \alpha$ & $\begin{array}{l}\text { Sense: 5'-AAG AAG CTG AGC GAG TGT-3' } \\
\text { Antisense: 5'-GGA GGA AGT CCA ATG TC-3' }\end{array}$ & 265 \\
\hline $\operatorname{Bcl}-2 \alpha$ & $\begin{array}{l}\text { Sense: 5'-CTT CTC CCG CCG CTA C-3' } \\
\text { Antisense: 5'-CTG GGG CCG TAC AGT TC-3' }\end{array}$ & 306 \\
\hline BIRC-2 & $\begin{array}{l}\text { Sense: 5'-CAG AAA GGA GTC TTG CTC GTG-3' } \\
\text { Antisense: 5'-CCG GTG TTC TGA CAT AGC ATC-3' }\end{array}$ & 536 \\
\hline BIRC-3 & $\begin{array}{l}\text { Sense: 5'-GGG AAC CGA AGG ATA ATG CT-3' } \\
\text { Antisense: 5'-ACT GGC TTG AAC TTG ACG GAT-3' }\end{array}$ & 368 \\
\hline BIRC-4 & $\begin{array}{l}\text { Sense: 5'-AAT GCT GCT TTG GAT GAC CTG-3' } \\
\text { Antisense: 5'-ACC TGT ACT CAG CAG GTA CTG-3' }\end{array}$ & 470 \\
\hline BIRC-5 & $\begin{array}{l}\text { Sense: 5'-GCC CCA CTG AGA ACG-3' } \\
\text { Antisense: 5'-CCA GAG GCC TCA ATC C-3' }\end{array}$ & 302 \\
\hline BIRC-6 & $\begin{array}{l}\text { Sense: 5'-AGC CGA AGG ATA GCG A-3' } \\
\text { Antisense: 5'-GCC ATC CGC CTT AGA A-3' }\end{array}$ & 385 \\
\hline BIRC-7 & $\begin{array}{l}\text { Sense: 5'-GCC TCC TTC TAT GAC T-3' } \\
\text { Antisense: 5'-CGT CTT CCG GTT CT-3' }\end{array}$ & 283 \\
\hline BIRC-8 & $\begin{array}{l}\text { Sense: 5'-GTG AGC GCT CAG AAA GAC ACT AC-3' } \\
\text { Antisense: 5'-CAC ATG GGA CAT CTG TCA ACT G-3' }\end{array}$ & 209 \\
\hline m-Calpain & $\begin{array}{l}\text { Sense: 5'-CCC TCC CAA CCT GTT CAA G-3' } \\
\text { Antisense: 5'-GCC TCC AGT TCC CAT CCA-3' }\end{array}$ & 440 \\
\hline Calpastatin & $\begin{array}{l}\text { Sense: 5'-TCA CCT GTG GGT CGC CTA C-3' } \\
\text { Antisense: 5'-GCT CTG GCA ATA GTG GTT TTC C-3' }\end{array}$ & 351 \\
\hline
\end{tabular}

IgG conjugated with alkaline horseradish peroxidase (HRP) (ICN Biomedicals, Aurora, OH, USA) except in the case of calpain and $\alpha$-spectrin where it was goat anti-rabbit IgG conjugated with alkaline HRP (ICN Biomedicals).

Western blot analysis of specific proteins. Western blot analysis was performed, as we described previously $(10,11)$. The autoradiograms were scanned using Photoshop software (Adobe Systems, Seattle, WA, USA) and the optical density (OD) of each band was determined using Quantity One software (Bio-Rad, Hercules, CA, USA).

Colorimetric assay for the measurement of caspase-8, -9, and -3 activities. Measurements of caspase activities in cells were performed with the commercially available caspase-8, -9 and -3 assay kits. The colorimetric assays were based on the hydrolysis of the Ac-IETD- $p$ NA by caspase-8, AcLEHD- $p$ NA by caspase- 9 , and Ac-DEVD- $p$ NA by caspase-3, resulting in the release of the $p$-nitroaniline (p-NA) moiety using the commercially available colorimetric assay kits (Sigma Chemical). Concentration of the $p$-NA released from the substrate was calculated from the absorbance at $405 \mathrm{~nm}$.
Statistical analysis. All results obtained from different treatments of SH-SY5Y cells were analyzed using StatView software (Abacus Concepts, Berkeley, CA, USA). Data were expressed as mean \pm standard error of mean (SEM) of separate experiments $(n \geq 3)$ and compared by one-way analysis of variance (ANOVA) followed by Fisher's post hoc test. Significant difference between control (CTL) and EGCG, and CTL and GST was analyzed. Difference between two treatments was considered significant at $\mathrm{P} \leq 0.05$.

\section{Results}

Retinoids induced differentiation with downregulation of telomerase and $\mathrm{N}-\mathrm{Myc}$ but overexpression of neurofilament protein $(N F P)$. We examined the morphological and biochemical features of neuronal differentiation in SH-SY5Y cells following treatment with retinoids (Fig. 1). ATRA, 13-CRA, or 4-HPR induced morphological features of neuronal differentiation in SH-SY5Y cells (Fig. 1a). Telomerase activity was evaluated by the TRAP assay (Fig. 1b). Our results showed inhibition of telomerase activity in SH-SY5Y cells following treatment with retinoids. We also used Western blotting to examine the level of expression of 
$\mathbf{a}$

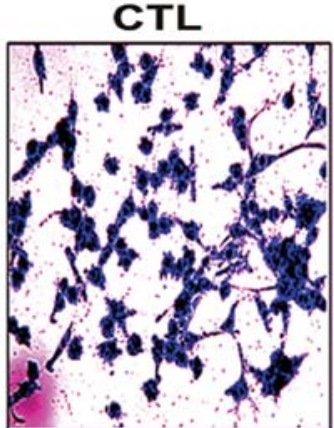

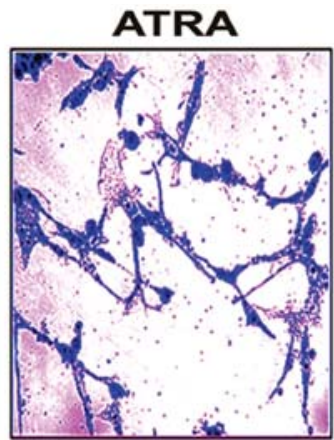
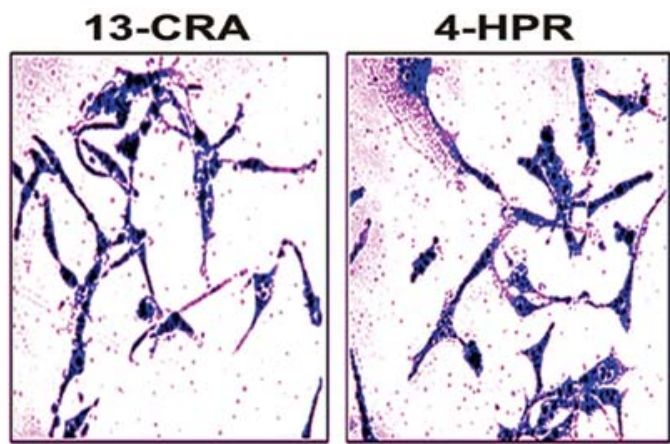

b

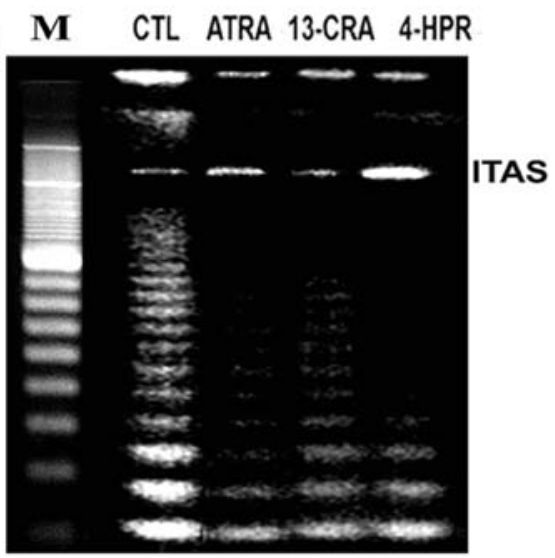

C CTL ATRA 13-CRA 4-HPR
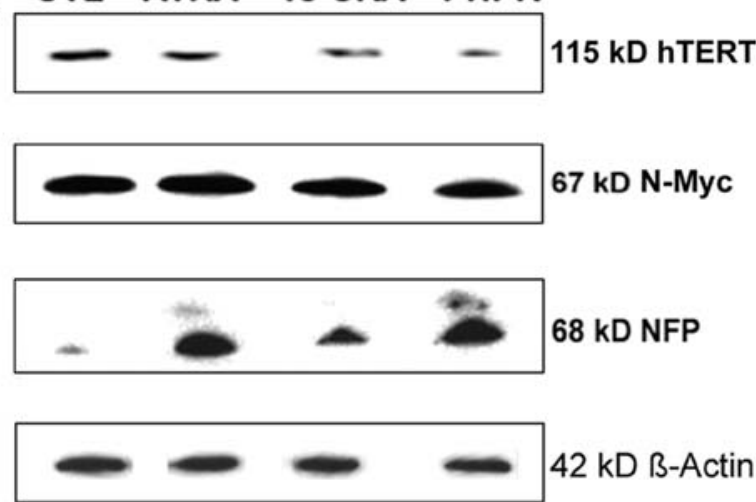

Figure 1. Morphological and biochemical features of neuronal differentiation in SH-SY5Y cells following treatment with retinoids. Treatment with retinoid (7 days): control (CTL), $1 \mu \mathrm{M}$ ATRA, $1 \mu \mathrm{M}$ 13-CRA, and $0.5 \mu \mathrm{M}$ 4-HPR. (a) Methylene blue staining to identify morphological features of neuronal differentiation. (b) Application of TRAP assay to determine any decrease in the telomerase activity due to differention. M=20 to 1000 bp ladder, and ITAS=internal telomerase assay standard. (c) Western blotting to examine levels of hTERT, N-Myc, NFP, and ß-actin.

hTERT (the catalytic subunit of telomerase), which was downregulated following treatment with retinoids (Fig. 1c). Inhibition of N-Myc expression results in suppression of cell proliferation and induction of differentiation. Our results showed that the expression of N-Myc was decreased due to treatment with reinoids, compared with parental SH-SY5Y cells (Fig. 1c). Expression of $68 \mathrm{kDa}$ NFP occurs in neuroblasts with signs of differentiation, but not in immature small, round cells. Also, $68 \mathrm{kDa}$ NFP is present in cell bodies as well as in cytoplasmic processes of differentiated neuroblasts. The presence of $68 \mathrm{kDa} \mathrm{NFP}$ is related to the degree of differentiation of tumor cells. Our Western blotting indicated increase in expression of $68 \mathrm{kDa}$ NFP in differentiated SHSY5Y cells (Fig. 1c). The uniform level of expression of $\beta$ actin was used as a loading control. Thus, our findings suggested that ATRA, 13-CRA, or 4-HPR at a low dose induced differentiation with downregulation of telomerase and N-Myc and overexpression of $68 \mathrm{kDa}$ NFP in SH-SY5Y cells.

Detection of morphological and biochemical features of apoptosis following single and double treatments. The amount of apoptotic death was determined using Wright staining and ApopTag assay (Fig. 2). Wright staining and ApopTag assay were used to demonstrate apoptotic features morphologically and biochemically, respectively. Treatment of SH-SY5Y cells with EGCG or GST for $24 \mathrm{~h}$ induced apoptotic death with manifestation of morphological features as evident from Wright staining (Fig. 2a) and DNA fragmentation as evident from ApopTag assay (Fig. 2b). Following ApopTag assay, control cells showed little or no brown color confirming almost absence of apoptosis. But cells treated with EGCG or GST for $24 \mathrm{~h}$ demonstrated prominent brown color apoptotic cells. Treatment of cells with a low dose of ATRA, 13-CRA, or 4-HPR for 7 days did not induce apoptosis but increased sensitivity of differentiated cells to EGCG or GST for increasing the amounts of apoptosis, as determined on the basis of ApopTag assay (Fig. 2c). The results showed that the combination of a retinoid and a flavonoid worked synergistically for increasing apoptosis in malignant neuroblastoma cells.

Retinoids reduced the levels of inflammatory and angiogenic factors. Increased expression of the inflammatory mediator $\mathrm{NF}-\kappa \mathrm{B}$ may be correlated to malignant growth of neuroblastoma. Although the anti-inflammatory effect of retinoids has been investigated for several decades, the underlying mechanisms responsible for this effect are largely unknown. In this study, we demonstrated that ATRA, 13-CRA, or 4-HPR inhibited inflammatory response in SH-SY5Y cells by decreasing the expression of NF-кB (Fig. 3). Moreover, our results suggested that the anti-inflammatory effect of ATRA, 13-CRA, or 4-HPR could be potentiated by EGCG or GST in $\mathrm{SH}-\mathrm{S}$ Y 5 Y cells. Thus, targeting the inhibition of NF- $\mathrm{B}$ activation would lead to the development of new strategy for treatment of neuroblastoma. Downregulation of the angiogenic factor VEGF in cancer cells by retinoids may contribute to the therapeutic effects (12). Our data demonstrated that 
a

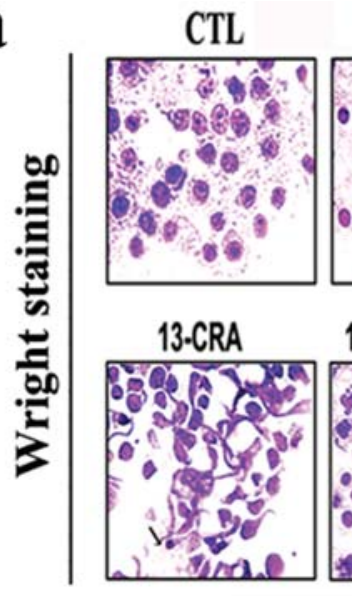

b

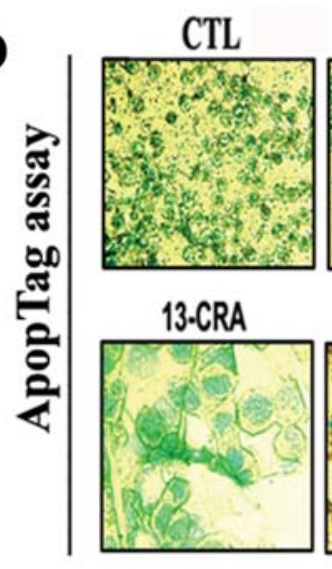

EGCG

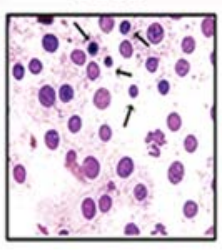

13-CRA+ EGCG
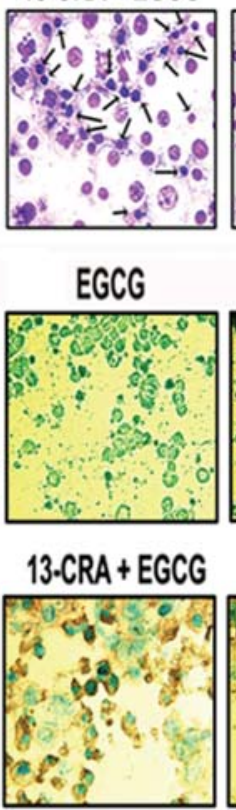

GST
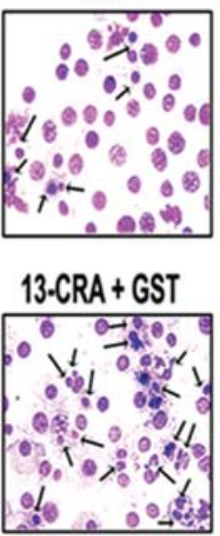

\section{GST}
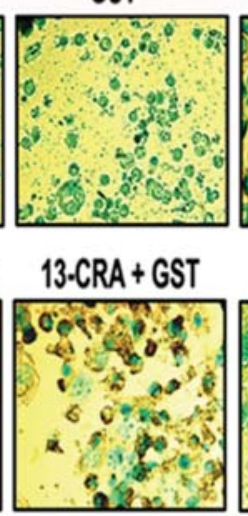

ATRA

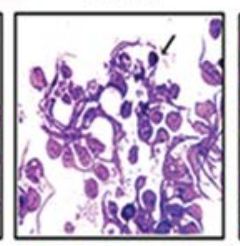

4.HPR

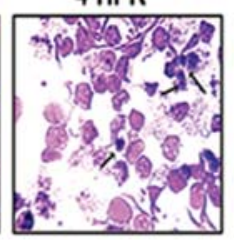

ATRA

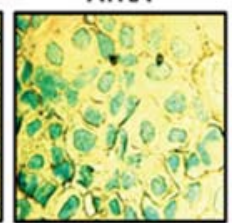

4.HPR

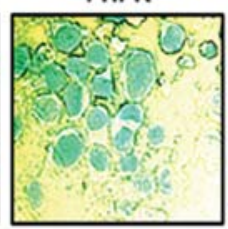

ATRA + EGCG

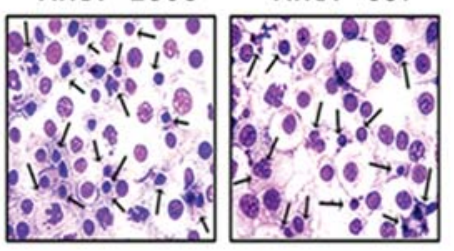

$4 \cdot H P R+E G C G \quad 4 \cdot H P R+G S T$

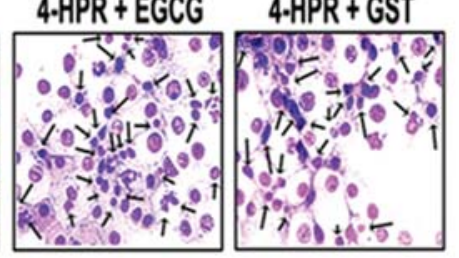

ATRA + EGCG ATRA + GST

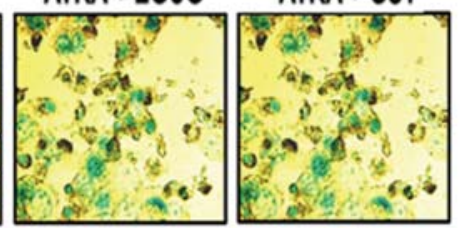

4.HPR + EGCG 4.HPR + GST

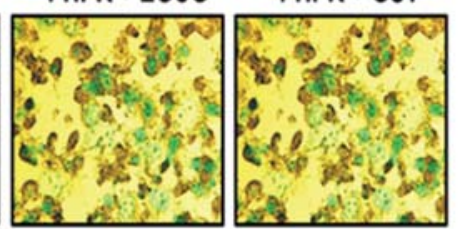

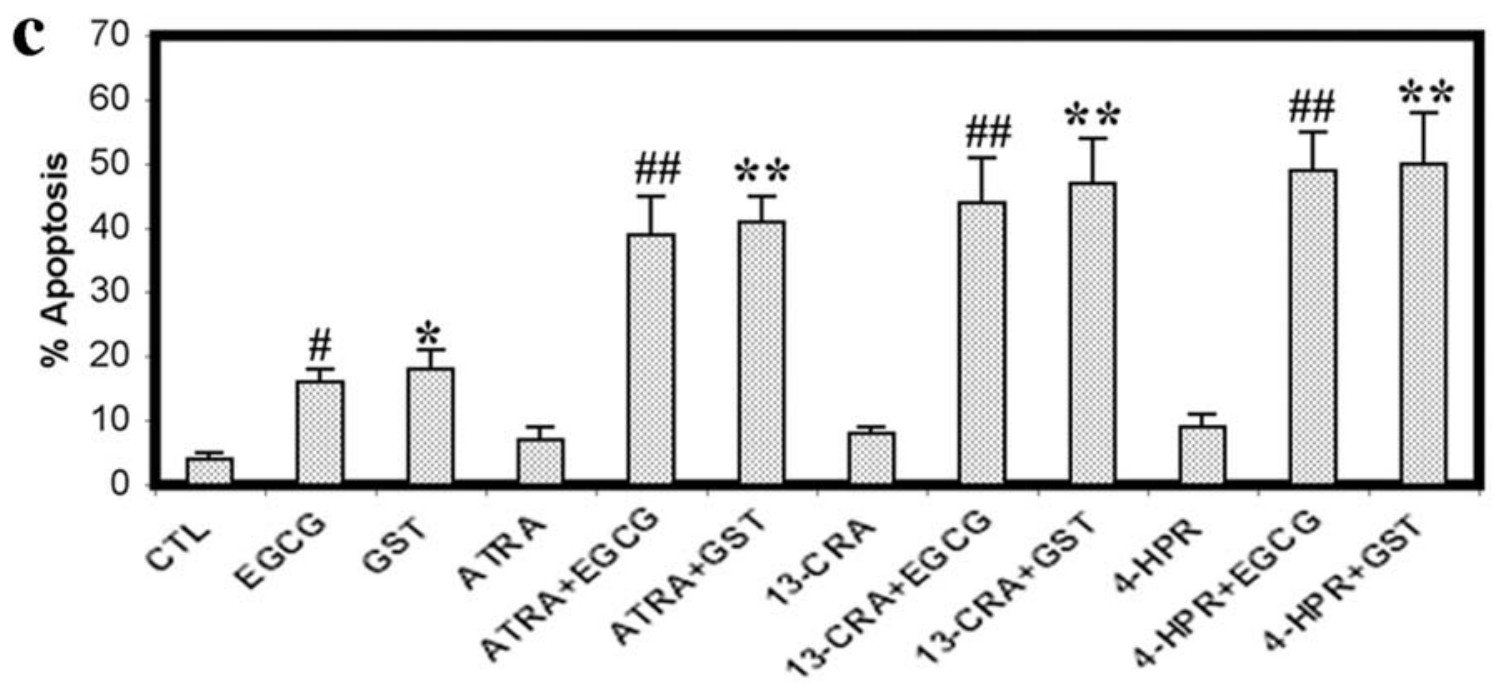

Figure 2. Morphological and biochemical features of apoptosis in SH-SY5Y cells. Treatment with retinoid (7 days) and flavonoid (24 h): CTL, $25 \mu \mathrm{M}$ EGCG, $25 \mu \mathrm{M}$ GST, $1 \mu \mathrm{M}$ ATRA, $1 \mu \mathrm{M}$ ATRA $+25 \mu \mathrm{M}$ EGCG, $1 \mu \mathrm{M}$ ATRA $+25 \mu \mathrm{M}$ GST, $1 \mu \mathrm{M} 13-\mathrm{CRA}, 1 \mu \mathrm{M} 13-\mathrm{CRA}+25 \mu \mathrm{M}$ EGCG, $1 \mu \mathrm{M} 13-\mathrm{CRA}+25 \mu \mathrm{M}$ GST, $0.5 \mu \mathrm{M}$ 4-HPR, $0.5 \mu \mathrm{M}$ 4-HPR $+25 \mu \mathrm{M}$ EGCG, and $0.5 \mu \mathrm{M}$ 4-HPR $+25 \mu \mathrm{M}$ GST. (a) Wright staining for morphological features of apoptosis. (b) ApopTag assay for labeling of DNA fragmentation in apoptotic cells. (c) Bar diagram to show the percentage of apoptosis. Significant difference between control (CTL) and EGCG is indicated by ${ }^{\#} \mathrm{P}<0.05$ while between CTL and retinoid + ECCG by ${ }^{\# \#} \mathrm{P}<0.001$. Significant difference between CTL and GST is indicated by ${ }^{*} \mathrm{P}<0.05$ while between CTL and retinoid + GST by ${ }^{* *} \mathrm{P}<0.001$.

retinoids could be potent inhibitors of VEGF production in human neuroblastoma cells (Fig. 3). Thus, one of the molecular mechanisms by which retinoids inhibited VEGF expression appeared to correlate with the inhibition of NF- $\mathrm{KB}$ activation. Our studies demonstrated that the combination of a retinoid (ATRA, 13-CRA, or 4-HPR) and a flavonoid (EGCG or GST) could reduce the levels of NF- $\mathrm{KB}$ and VEGF so as to favor induction of apoptosis in SH-SY5Y cells.
Treatment of neuroblastoma cells with EGCG induced caspase- 8 activation and activity. We examined the induction of death receptor pathway of apoptosis in the caspase- 8 activation and activity following the treatments of SH-SY5Y cells (Fig. 4). Caspase-8 is the apical caspase in death receptor pathway of apoptosis. Caspase- 8 is activated upstream of caspase- 3 and has been implicated to play a prominent role in potentiating the mitochondria-mediated pathway of apoptosis. 


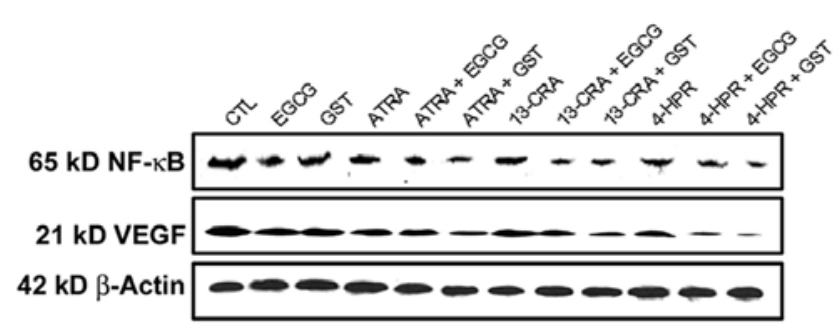

Figure 3. Western blotting to examine the levels of inflammatory and angiogenic factors in SH-SY5Y cells. Treatment with retinoid (7 days) and flavonoid (24 h): CTL, $25 \mu \mathrm{M}$ EGCG, $25 \mu \mathrm{M}$ GST, $1 \mu \mathrm{M}$ ATRA, $1 \mu \mathrm{M}$ ATRA $+25 \mu \mathrm{M}$ EGCG, $1 \mu \mathrm{M}$ ATRA $+25 \mu \mathrm{M}$ GST, $1 \mu \mathrm{M}$ 13-CRA, $1 \mu \mathrm{M}$ 13-CRA $+25 \mu \mathrm{M}$ EGCG, $1 \mu \mathrm{M}$ 13-CRA $+25 \mu \mathrm{M}$ GST, $0.5 \mu \mathrm{M}$ 4-HPR, $0.5 \mu \mathrm{M} 4-\mathrm{HPR}+25 \mu \mathrm{M}$ EGCG , and $0.5 \mu \mathrm{M} 4-\mathrm{HPR}+25 \mu \mathrm{M}$ GST Representative Western blots to show levels of NF-kB, VEGF, and B-actin.

Our Western blotting showed that treatment of SH-SY5Y cells with EGCG induced generation of $18 \mathrm{kDa}$ caspase- 8 fragment indicating the caspase- 8 activation (Fig. 4a). Pretreatment of the cells with a retinoid dramatically increased the action of EGCG for caspase- 8 activation. B-Actin expression was monitored to ensure that equal amounts of protein were loaded in all lanes (Fig. 4a). Further, our colorimetric assay showed that caspase- 8 activity was increased in the cells after treatment with EGCG (Fig. 4b). Combination of a retinoid (ATRA, 13-CRA, or 4-HPR) and EGCG highly induced caspase- 8 activation and activity

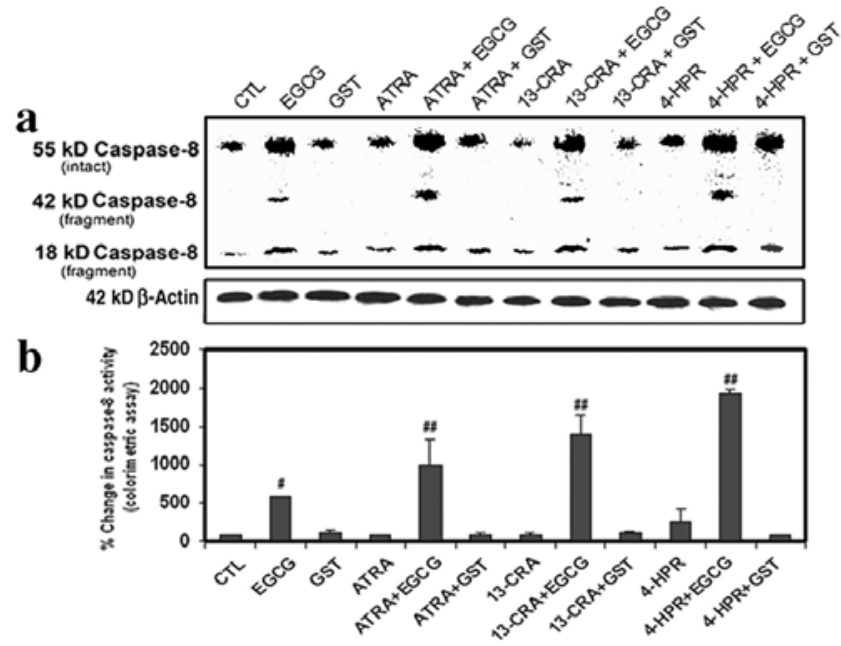

Figure 4. Determination of caspase-8 activation and activity in SH-SY5Y cells. Treatment with retinoid (7 days) and flavonoid (24 h): CTL, $25 \mu \mathrm{M}$ EGCG, $25 \mu \mathrm{M}$ GST, $1 \mu \mathrm{M}$ ATRA, $1 \mu \mathrm{M}$ ATRA $+25 \mu \mathrm{M}$ EGCG, $1 \mu \mathrm{M}$ ATRA $+25 \mu \mathrm{M}$ GST, $1 \mu \mathrm{M}$ 13-CRA, $1 \mu \mathrm{M}$ 13-CRA $+25 \mu \mathrm{M}$ EGCG, $1 \mu \mathrm{M}$ 13-CRA $+25 \mu \mathrm{M}$ GST, $0.5 \mu \mathrm{M} 4-\mathrm{HPR}, 0.5 \mu \mathrm{M} 4-\mathrm{HPR}+25 \mu \mathrm{M} \mathrm{EGCG}$, and $0.5 \mu \mathrm{M} 4-\mathrm{HPR}+25 \mu \mathrm{M}$ GST. (a) Representative Western blots to show levels of caspase- 8 and B-actin. (b) Determination of caspase- 8 activity by colorimetric assay.

(Fig. 4). Notably, GST alone or in combination with a retinoid did not induce death receptor-mediated pathway of apoptosis.

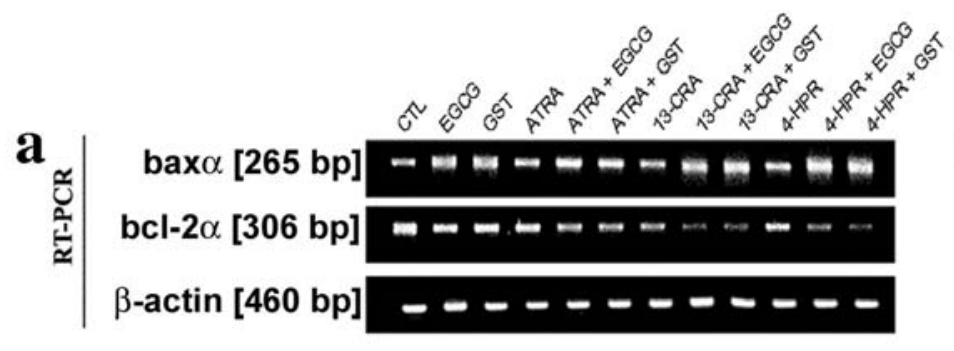

b

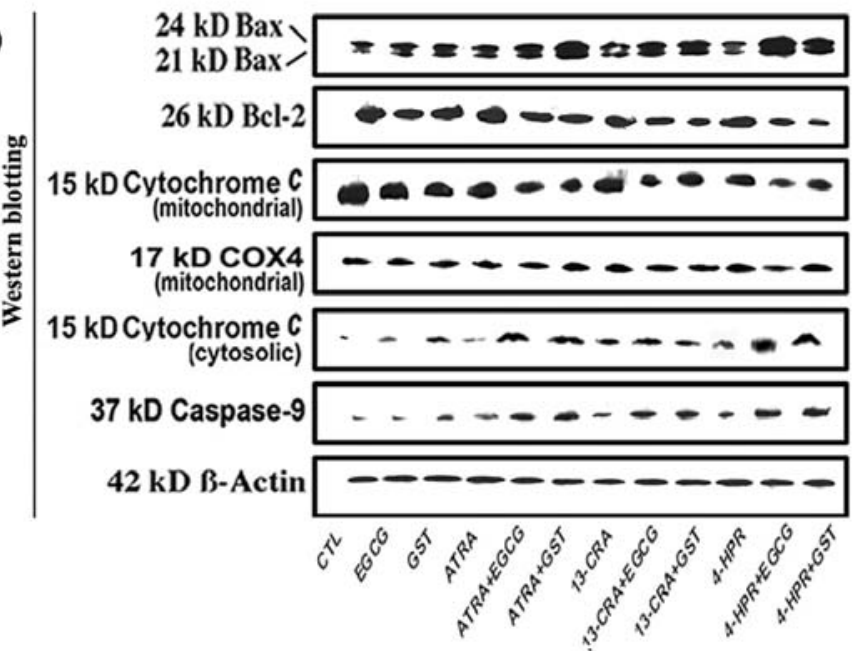

C

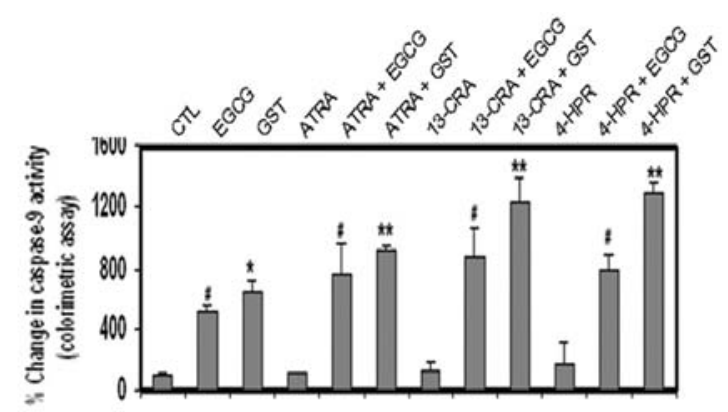

d

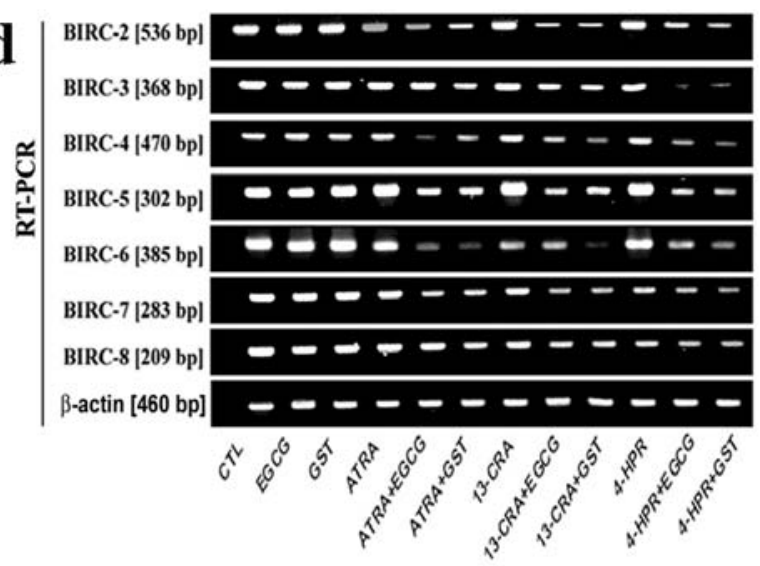

Figure 5. Examination of mitochondrial pathway of apoptosis in SH-SY5Y cells. Treatment with retinoid (7 days) and flavonoid (24 h): CTL, $25 \mu \mathrm{M}$ EGCG, $25 \mu \mathrm{M}$ GST, $1 \mu \mathrm{M}$ ATRA, $1 \mu \mathrm{M}$ ATRA $+25 \mu \mathrm{M}$ EGCG, $1 \mu \mathrm{M}$ ATRA $+25 \mu \mathrm{M}$ GST, $1 \mu \mathrm{M}$ 13-CRA, $1 \mu \mathrm{M}$ 13-CRA $+25 \mu \mathrm{M}$ EGCG, $1 \mu \mathrm{M} 13-\mathrm{CRA}+25 \mu \mathrm{M}$ GST, $0.5 \mu \mathrm{M}$ 4-HPR, $0.5 \mu \mathrm{M}$ 4-HPR $+25 \mu \mathrm{M}$ EGCG, and $0.5 \mu \mathrm{M}$ 4-HPR $+25 \mu \mathrm{M}$ GST. (a) The representative gel pictures with RT-PCR products to show the mRNA levels of bax $\alpha$, bcl-2 $\alpha$, and B-actin. (b) Representative Western blots to show levels of Bax, Bcl-2, cytochrome $c$, COX4, caspase-9, and $\beta$-actin. (c) Determination of caspase-9 activity using a colorimetric assay. (d) Representative gel pictures with RT-PCR products to show the mRNA levels of BIRC-2 to BIRC-8 and B-actin. 

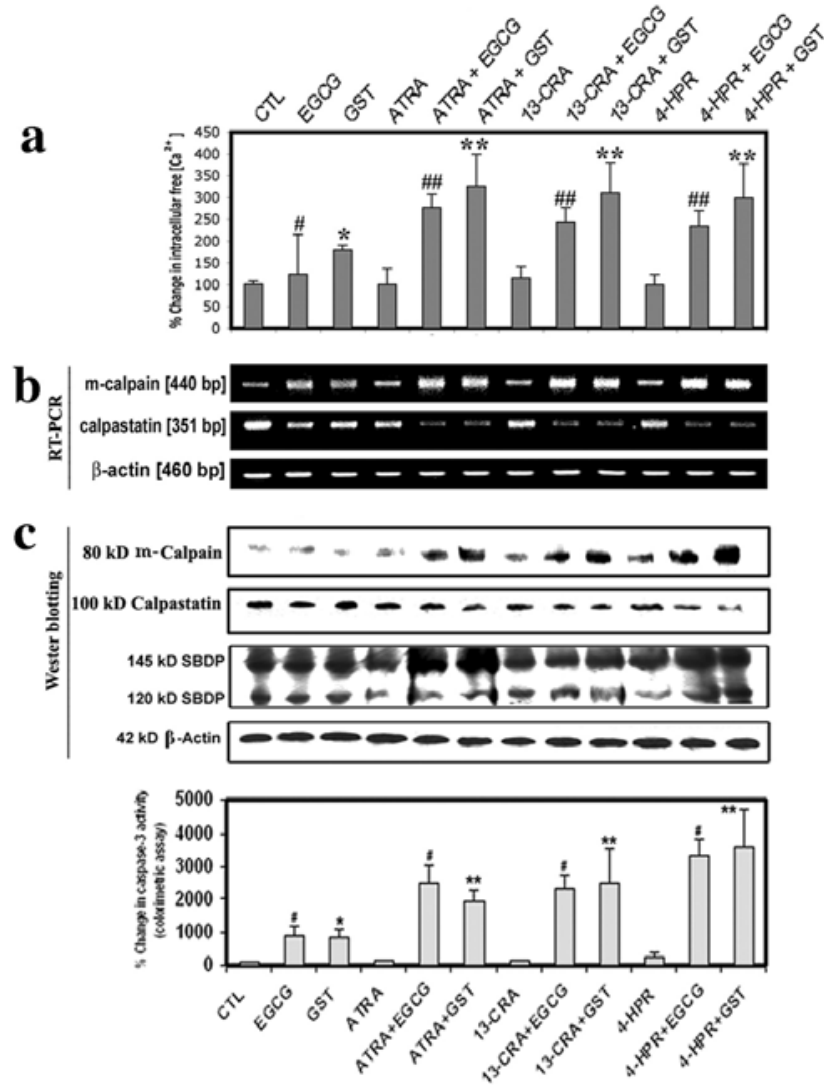

Figure 6. Determination of intracellular free $\left[\mathrm{Ca}^{2+}\right]$ and activities of calpain and caspase-3 in SH-SY5Y cells. Treatment with retinoid (7 days) and flavonoid (24 h): CTL, $25 \mu \mathrm{M}$ EGCG, $25 \mu \mathrm{M}$ GST, $1 \mu \mathrm{M}$ ATRA, $1 \mu \mathrm{M}$ $\mathrm{ATRA}+25 \mu \mathrm{M}$ EGCG, $1 \mu \mathrm{M}$ ATRA $+25 \mu \mathrm{M}$ GST, $1 \mu \mathrm{M} 13-\mathrm{CRA}, 1 \mu \mathrm{M}$ 13-CRA $+25 \mu \mathrm{M}$ EGCG, $1 \mu \mathrm{M} 13-\mathrm{CRA}+25 \mu \mathrm{M}$ GST, $0.5 \mu \mathrm{M} 4$-HPR, $0.5 \mu \mathrm{M} 4-\mathrm{HPR}+25 \mu \mathrm{M}$ EGCG, and $0.5 \mu \mathrm{M} 4-\mathrm{HPR}+25 \mu \mathrm{M}$ GST. (a) Determination of percentage of increase in intracellular-free $\left[\mathrm{Ca}^{2+}\right]$. (b) Representative gel pictures with RT-PCR products to show the mRNA levels of m-calpain, calpastain, and $\beta$-actin. (c) Representative Western blots to show the levels of m-calpain, calpastatin, SBDP, and B-actin. (d) Determination of caspase- 3 activity using a colorimetric assay.

Induction of apoptosis with activation of mitochondriadependent caspase cascade. Members of the Bcl-2 family, with proteins such as Bax functioning as inducer of apoptosis and proteins such as Bcl-2 as suppressor of cell death, play major roles in governing the mitochondria-dependent caspase cascade. We examined the level of expression or location of the molecules that activate the mitochondria-dependent pathway of apoptosis (Fig. 5). Our results showed that cells treated with a flavonoid (EGCG or GST) increased the Bax (pro-apoptotic protein) expression at mRNA (Fig. 5a) and protein (Fig. 5b) levels. Importantly, treatment of cells with the combination of a retinoid (ATRA, 13-CRA, or 4-HPR) and a flavonoid (EGCG or GST) most effectively increased Bax expression and decreased $\mathrm{Bcl}-2$ expression to trigger mitochondria-dependent caspase cascade. Our results showed that treatment of cells with the combination of retinoid and flavonoid clearly caused the disappearance of $15 \mathrm{kDa}$ cytochrome $c$ from the mitochondrial fraction (Fig. 5b), indicating mitochondrial release of cytochrome $c$. Due to the release from mitochondria, $15 \mathrm{kDa}$ cytochrome $c$ appeared in the cytosolic fraction (Fig. 5b). We monitored the level of expression of COX4 (Fig. 5b) as an internal control in mitochondrial fraction (13). ß-Actin expression was examined to ensure that equal amounts of cytosolic protein were loaded in all lanes. The release of cytochrome $c$ from mitochondria to cytosol could cause activation of mitochondria-dependent caspase cascade. Indeed, we observed that treatments of SH-SY5Y cells with a flavonoid, especially with the combination of retinoid and flavonoid, increased caspase- 9 activation with generation of active $37 \mathrm{kDa}$ caspase- 9 fragment as revealed by Western blotting (Fig. 5b) and also increased the total caspase- 9 activity as confirmed by a colorimetric assay (Fig. 5c).

As any decrease in BIRC contents could favor sustained activation of caspase cascade, we used RT-PCR experiments to assess levels of expression of BIRC-2 to BIRC-8 in SHSY5Y cells after the treatments (Fig. 5d). Our results showed that treatment with the combination of retinoid and flavonoid decreased the levels of expression of BIRC-2 to BIRC-6 in SH-SY5Y cells. However, the levels of BIRC-7 and BIRC-8 did not go down dramatically after the treatments. The results indicated that EGCG or GST induced apoptosis in differentiated SH-SY5Y cells with dramatic decrease in levels of expression of BIRC-2 to BIRC-6.

Treatments increased intracellular free $\left[\mathrm{Ca}^{2+}\right]$ and activities of calpain and caspase-3. We examined the consequences of treatments, especially combination of retinoid and flavonoid, in alterations of the intracellular free $\left[\mathrm{Ca}^{2+}\right]$ and activities of calapin and caspase-3 (Fig. 6). We used Fura-2 assay to determine the intracellular free $\left[\mathrm{Ca}^{2+}\right]$ in SH-SY5Y cells (Fig. 6a). Treatment with EGCG or GST for $24 \mathrm{~h}$ increased intracellular free $\left[\mathrm{Ca}^{2+}\right]$ significantly in undifferentiated cells and very significantly in differentiated cells, compared with control cells (Fig. 6a). Our results showed that treatments increased m-calpain at mRNA and protein levels (Fig. 6b). The endogenous calpain inhibitor calpastatin is fragmented by calpain and caspase(s) to various extent during apoptosis (14). Our result showed that the levels of mRNA (Fig. 6b) and protein (Fig. 6c) of calpastain were decreased after the treatments. The degradation of $270 \mathrm{kDa} \alpha$-spectrin to $145 \mathrm{kDa}$ spectrin breakdown product (SBDP) and $120 \mathrm{kDa}$ SBDP has been attributed to activation of calpain and caspase-3, respectively (6). So, we performed Western blotting to determine activities of calpain and caspase-3 in the generation of calpain-specific $145 \mathrm{kDa}$ SBDP and caspase-3-specific $120 \mathrm{kDa}$ SBDP, respectively (Fig. 6c). Treatment of the cells with a flavonoid (EGCG or GST), especially combination of retinoid and flavonoid, caused an increase in $145 \mathrm{kDa}$ SBDP and $120 \mathrm{kDa}$ SBDP suggesting increased activity of calapin and caspase-3, respectively. Moreover, we used a colorimetric assay to confirm that combination of retinoid and flavonoid worked synergistically to increase caspase-3 activity in SH-SY5Y cells (Fig. 6d). Importantly, our results showed that combination of 4-HPR and GST was the most suitable treatment for increasing both proteolytic activity and apoptosis in human malignant neuroblastoma cells.

\section{Discussion}

Chemotherapy with a single agent may be limited by both toxicity and lack of potency. Therefore, combination 
chemotherapeutic strategies are currently being explored to reduce toxicity and enhance therapeutic efficacy. For many years, it has been known that exposure of neuroblastoma cells to a retinoid causes decrease in tumor cell proliferation and induces differentiation (15). There are no clear roadmaps yet for prioritizing which retinoid or combination strategy should be put forward for clinical evaluation. Flavonoids have been reported to exert multiple effects on signal transduction pathways, cell-cycle regulatory molecules, and cell growth in diverse cell lines. Upregulation of N-Myc plays an important role in promoting proliferation of neuroblastoma cells (16). Here, we observed that a low dose of a retinoid (ATRA, 13-CRA or 4-HPR) induced neuronal differentiation with downregulation of N-Myc expression and telomerase activity but overexpression of $68 \mathrm{kDa}$ NFP in SH-SY5Y cells (Fig. 1). Treatment with a retinoid inhibited not only N-Myc expression and telomerase activity in neuroblastoma cells (Fig. 1) but also increased sensitivity to a flavonoid (EGCG or GST) for increasing the amount of apoptosis (Fig. 2).

Angiogenesis is necessary for cancer growth and dissemination. In addition to angiogenesis, it has become increasingly clear that inflammation is a key component in cancer insurgence that can promote angiogenesis. It is now known that NF- $\mathrm{\kappa B}$ belongs to a family of transcription factors (17), which play central roles in the expression of genes involved in cell mobilization, proliferation, and inflammation. In particular, NF- $\mathrm{KB}$ activation appears to drive a number of inflammatory diseases including cancers. Thus, targeting $\mathrm{NF}-\kappa \mathrm{B}$ activation would lead to the development of new therapeutic strategy that would provide novel treatment for these diseases. Our results showed a decrease in cytotolic level of NF- $\mathrm{kB}$ in SH-SY5Y cells after the treatments (Fig. 3). Thus, the repression of the $\mathrm{NF}-\kappa \mathrm{B}$ pathway suggests an antiinflammatory effect of these compounds. Our results also showed for the first time that combination of a retinoid and a flavonoid very effectively downregulated the angiogenic factor VEGF in SH-SY5Y cells (Fig. 3).

Caspase- 8 activation acts as a key determinant for induction of apoptosis by some cytotoxic drugs (18). The resistance of neuroblastoma cells to anti-cancer therapy has been related to absent or reduced caspase- 8 expression. We reported herein that SH-SY5Y cells constitutively express normal caspase- 8 and that activation of caspase- 8 is a key determinant in induction of apoptotic death by EGCG in undifferentiated and especially in differentiated SH-SY5Y cells (Fig. 4). Previous studies showed that green tea polyphenols induced apoptosis in human prostate carcinoma cells and monocytic leukemia U937 cells due to caspase-8 activation (19). Generally, green tea polyphenol induces death receptor-mediated caspase- 8 activation followed by caspase- 3 activation. We found that EGCG activated caspase-8 in SH-SY5Y cells (Fig. 4), indicating involvement of death receptor pathway of apoptosis.

Pro-apoptotic and anti-apoptotic members of the Bcl-2 family regulate the release of cytochrome $c$ from the mitochondrial intermembrane space into the cytosol. Cytochrome $c$ then interacts with the pro-caspase- 9 and Apaf-1 to activate caspase- 9 to switch on caspase-3 activity leading to apoptosis. So, we examined changes in expression of pro-apoptotic Bax and anti-apoptotic Bcl-2 at mRNA and protein levels (Fig. 5). Treatment of cells with a flavonoid (EGCG or GST), especially combination of a retinoid and a flavonoid, increased total Bax expression and decreased Bcl-2 expression (Fig. 5) resulting in increase in Bax:Bcl-2 ratio (data not shown) to promote mitochondrial release of proapoptotic factors. The mitochondrial involvement in apoptosis was manifested in the disappearance of $15 \mathrm{kDa}$ cytochrome $c$ from the mitochondria and its concurrent appearance in the cytosol (Fig. 5). As an internal control, we monitored expression of COX4 in mitochondrial fraction whereas $\beta$-actin expression in cytosolic fraction. The mitochondrial release of cytochrome $c$ into the cytosol could cause activation of caspase-9. Treatments with EGCG or GST and also combination of a retinoid and EGCG or GST increased active $37 \mathrm{kDa}$ caspase-9 fragment as detected by Western blotting (Fig. 5b) and also increased caspase-9 activity as determined by colorimetric assay (Fig. 5c). The inhibitory effects of various BIRC proteins on caspases and apoptosis have been examined in different cell culture models (20). We examined changes in the levels of BIRC expression and found downregulation of BIRC-2 to BIRC-6 (Fig. 5) to promote apoptosis.

Previously, it has been reported that a novel $\mathrm{Ca}^{2+}$-mediated calpain-dependent apoptotic pathway exists in breast cancer cells and also regulation of intracellular free $\left[\mathrm{Ca}^{2+}\right]$ in normal and cancer mammary epithelial cells is different (21). Our findings provide evidence for a sustained increase in intracellular free $\left[\mathrm{Ca}^{2+}\right]$ for activation of the $\mathrm{Ca}^{2+}$-dependent calpain for induction of apoptotic mechanism in SH-SY5Y cells following treatment with EGCG or GST alone and in combination with a retinoid (Fig. 6). Calpain can play a dual role, mediation of $\mathrm{Ca}^{2+}$ influx and proteolysis subsequent to $\mathrm{Ca}^{2+}$ influx, during cell death (22). Our findings support a direct relationship between an increase in intracellular free $\left[\mathrm{Ca}^{2+}\right]$ (Fig. 6a) and cell death with elevation of calpain expression and activity (Fig. 6b) following exposure to EGCG or GST. We also observed the decrease in calpastatin at mRNA and protein levels (Fig. 6). The increases in calpain and caspase- 3 activities were confirmed in the cleavage of $\alpha$-spectrin at specific sites for generating calpain-specific $145 \mathrm{kDa}$ SBDP and caspase-3-specific $120 \mathrm{kDa}$ SBDP. Overall, the results from this investigation showed that pretreatment of human malignant neuroblastoma cells with a retinoid induced differentiation and increased sensitivity to a flavonoid for increasing proteolytic activities for apoptotic death.

In conclusion, our present findings showed that the combination of a retinoid (especially 4-HPR) with a flavonoid (especially GST) could provide a novel therapeutic strategy for controlling the growth of human maliganant neuroblastoma cells.

\section{Acknowledgements}

This study was supported in part by the R01 grants (NS-57811 and CA-91460) from the National Institutes of Health (Bethesda, MD, USA) to S.K.R.

\section{References}

1. Brodeur GM: Meeting summary for advances in neuroblastoma research-2000. Med Pediatr Oncol 35: 727-728, 2000. 
2. Guzhova I, Hultquist A, Cetinkaya C, Nilsson K, Påhlman S and Larsson LG: Interferon-gamma cooperates with retinoic acid and phorbol ester to induce differentiation and growth inhibition of human neuroblastoma cells. Int J Cancer 94: 97-108, 2001.

3. Reynolds CP, Kane DJ, Einhorn PA, Matthay KK, Crouse VL, Wilbur JR, Shurin SB and Seeger RC: Response of neuroblastoma to retinoic acid in vitro and in vivo. Prog Clin Biol Res 366: 203-211, 1991.

4. Veal GJ, Errington J, Redfern CP, Pearson AD and Boddy AV: Influence of isomerisation on the growth inhibitory effects and cellular activity of 13-cis and all-trans retinoic acid in neuroblastoma cells. Biochem Pharmacol 63: 207-215, 2002

5. Lovat PE, Corazzari M, Goranov B, Piacentini M and Redfern CP: Molecular mechanisms of fenretinide-induced apoptosis of neuroblastoma cells. Ann NY Acad Sci 28: 81-89, 2004.

6. Das A, Banik NL and Ray SK: Mechanism of apoptosis with the involvement of calpain and caspase cascades in human malignant neuroblastoma SH-SY 5 Y cells exposed to flavonoids. Int J Cancer 119: 2575-2585, 2006.

7. Chen C, Shen G, Hebbar V, Hu R, Owuor ED and Kong AN Epigallocatechin-3-gallate-induced stress signals in HT-29 human colon adenocarcinoma cells. Carcinogenesis 24: 1369-1378, 2003.

8. Uchiyama $\mathrm{S}$ and Yamaguchi $\mathrm{M}$ : Genistein and zinc synergistically stimulate apoptotic cell death and suppress RANKL signaling-related gene expression in osteoclastic cells. J Cell Biochem 101: 529-542, 2007.

9. Brown A, Jolly P and Wei H: Genistein modulates neuroblastoma cell proliferation and differentiation through induction of apoptosis and regulation of tyrosine kinase activity and $\mathrm{N}$ myc expression. Carcinogenesis 19: 991-997, 1998.

10. Das A, Banik NL and Ray SK: Differentiation decreased telomerase activity in rat glioblastoma C6 cells and increased sensitivity to IFN- $\gamma$ and taxol for apoptosis. Neurochem Res 32: 2167-2183, 2007.

11. Das A, Banik NL and Ray SK: Retinoids induced astrocytic differentiation with down regulation of telomerase activity and enhanced sensitivity to taxol for apoptosis in human glioblastoma T98G and U87MG cells. J Neurooncol 87: 9-22, 2008.
12. Mantell DJ, Owens PE, Bundred NJ, Mawer EB and Canfield AE: $1 \alpha, 25$-dihydroxyvitamin $\mathrm{D}(3)$ inhibits angiogenesis in vitro and in vivo. Circ Res 87: 214-220, 2000.

13. Zhang D, Mott JL, Chang SW, Stevens M, Mikolajczak P and Zassenhaus HP: Mitochondrial DNA mutations activate programmed cell survival in the mouse heart. Am J Physiol Heart Circ Physiol 288: H2476-H2483, 2005.

14. Wang KK, Posmantur R, Nadimpalli R, Nath R, Mohan P Nixon RA, Talanian RV, Keegan M, Herzog L and Allen H: Caspase-mediated fragmentation of calpain inhibitor protein calpastatin during apoptosis. Arch Biochem Biophys 356: 187-196, 1998

15. Smith MA and Anderson B: Where to next with retinoids for cancer therapy? Clin Cancer Res 7: 2955-2957, 2001.

16. Raschellà G, Negroni A, Giubilei C, Romeo A, Ferrari S, Castello MA and Dominici C: Transcription of N-myc and proliferation-related genes is linked in human neuroblastoma. Cancer Lett 56: 45-51, 1991

17. Hoffmann A, Natoli G and Ghosh G: Transcriptional regulation via the NF-kB signaling module. Oncogene 25: 6706-6716, 2006.

18. Bozzo C, Sabbatini M, Tiberio R, Piffanelli V, Santoro C and Cannas M: Activation of caspase-8 triggers anoikis in human neuroblastoma cells. Neurosci Res 56: 145-153, 2006.

19. Roy M, Chakrabarty S, Sinha D, Bhattacharya RK and Siddiqi M: Anti-clastogenic, anti-genotoxic and apoptotic activity of epigallocatechin gallate: a green tea polyphenol. Mutat Res 523/524: 33-41, 2003.

20. Silke J and Vaux DL: Two kinds of BIR-containing protein inhibitors of apoptosis, or required for mitosis. J Cell Sci 114: 1821-1827, 2001.

21. Sergeev IN and Norman AW: Calcium as a mediator of apoptosis in bovine oocytes and preimplantation embryos. Endocrine 22: 169-175, 2003.

22. Ray SK, Fidan M, Nowak MW, Wilford GG, Hogan EL and Banik NL: Oxidative stress and $\mathrm{Ca}^{2+}$ influx upregulate calpain and induce apoptosis in PC12 cells. Brain Res 852: 326-334, 2000 . 